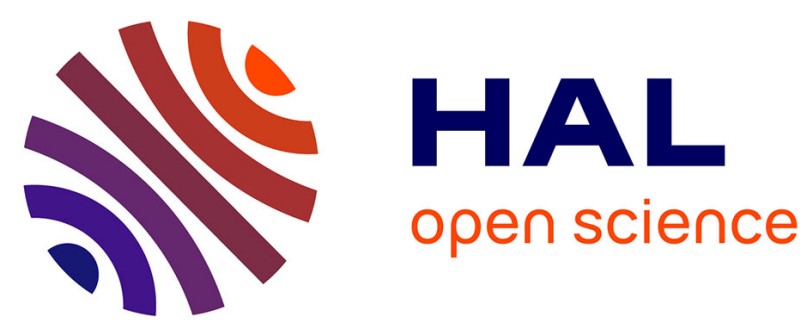

\title{
Dissipative Behaviour Analysis of Reprocessed Polyethylene Terephthalate using Digital Image Correlation and Updated Finite Element Analysis
}

\author{
A. S. Caro-Bretelle, P. Ienny, L. K. Nait-Ali, A. Bergeret
}

\section{- To cite this version:}

A. S. Caro-Bretelle, P. Ienny, L. K. Nait-Ali, A. Bergeret. Dissipative Behaviour Analysis of Reprocessed Polyethylene Terephthalate using Digital Image Correlation and Updated Finite Element Analysis. Strain, 2013, 49 (2), pp.135-146. 10.1111/str.12021 . hal-02949379

\author{
HAL Id: hal-02949379 \\ https://hal.science/hal-02949379
}

Submitted on 25 May 2021

HAL is a multi-disciplinary open access archive for the deposit and dissemination of scientific research documents, whether they are published or not. The documents may come from teaching and research institutions in France or abroad, or from public or private research centers.
L'archive ouverte pluridisciplinaire HAL, est destinée au dépôt et à la diffusion de documents scientifiques de niveau recherche, publiés ou non, émanant des établissements d'enseignement et de recherche français ou étrangers, des laboratoires publics ou privés. 


\title{
Dissipative Behaviour Analysis of Reprocessed Polyethylene Terephthalate using Digital Image Correlation and Updated Finite Element Analysis
}

\author{
A. S. Caro-Bretelle*, P. lenny*, L. K. Nait-Ali*† and A. Bergeret* \\ *Ecole des Mines d'Alès, Centre CMGD, 6 Avenue de Clavières, 30319 Alès, France \\ †Terre Armée Internationale, R\&D Division, I bis-rue du Petit Clamart, 78|48 Vélizy-Villacoublay, France
}

\begin{abstract}
Polyethylene terephthalate (PET) is a semi-crystalline polyester that is usually processed by conventional methods. However, the degradation of this polyester during the melting process impacts its macroscopic behaviour, which is particularly true for recycled PET that is subjected to multiple processes at the melting temperature by extrusion, injection-moulding or pelletizing. In this work, the impact of reprocessing on the mechanical properties of PET is studied. This approach requires exploring the influence of implementation on both its own mechanical performance factor and on the damage linked to the striction problem. An experimental protocol was developed to study large strain responses through a set of sequenced and instrumented uniaxial traction tests based on the standard ISO-5272-I-A and hourglass geometries. Updated finite element simulations were coupled with digital image correlation, thereby providing access to the parameters of a phenomenological model. This coupled approach enables researchers to understand both the complex shape of the stress-strain curve and the well-known dilatant mechanism that is observed during uniaxial deformation.
\end{abstract}

KEY WORDS: digital image correlation, mechanical properties, poly(ethylene terephthalate) reprocessing

\section{Introduction}

Poly(ethylene terephthalate) (PET) is a linear and semiaromatic polyester that is known for its high strength, transparency, good barrier properties and low cost. The use of PET has been significantly increasing, particularly in such applications as beverage bottles, engineering products, films and fibres. This polymer represents an important component of plastic waste. The PET recycling industry is the result of environmental pressure to improve waste management. Although the mechanical recycling of PET from food packaging is a good method to obtain a new product with a lower cost, this polymer is notably sensitive to hydrolytic, thermal and oxidative degradation reactions that induce chain-cleavage and/or cross linking during melt processing. Furthermore, high levels of contaminants (e.g. poly(vinyl chloride) and polyolefins adhesives) in recycled PET catalyse these mechanisms. The performance of reprocessed post-consumer PET depends on the optimisation of processing parameters to avoid degradation and ageing mechanisms, which involve the loss of mechanical properties: under tension, the occurrence of localisation phenomena (even at low strain) and the development of apparent plasticity and strain/stress heterogeneity.

This work studies the impact of microstructural degradation (during the multiple melt processing of recycled PET) on the mechanical behaviour of PET. To highlight the link between reprocessing and the loss of mechanical properties, optical, technical and phenomenological modelling approaches are simultaneously employed:

- Among many optical full-field techniques [1-3], digital image correlation (DIC $[4,5]$ ) is used to measure both inplane displacements and strain. The principle is based on images captured on the surface of the sample at two loading steps. By digitalisation, these two images are converted into different levels of light intensity. These digitised images are subsequently correlated by an algo- rithm to indicate the differences between them. Fullplane stress and transversal isotropy assumptions are used to take into account the volume variation commonly observed for these types of materials [6-9].

- Mechanical degradation characterisation is achieved by fitting parameters from a suitable phenomenological model. Other modelling alternatives are applied according to the scale of observation. Microscopic (such as D.N.L.R. for Distribution of Non-Linear Relaxations) and mesoscopic approaches require local information on the polymer microstructure [10-17]. In this paper, a phenomenological modelling approach [18-22] based on unified evolution of an elastic-plastic model under large strain is presented. As the plasticity assumption is isochoric, the dilatation phenomenon observed during the tensile test is introduced through the change in elastic parameters by a function of damage.

Although mechanical tests are performed on a macroscopic scale, by varying the sample geometries (ISO 5272-1-A and hourglass), it is possible to exhibit both macroscopic behaviour and local phenomenon of PET (such as striction) resulting from the microstructural mechanisms responsible for its gradual transformation during the loading. The experimental approach is thus based on

- the association of static loading/unloading experiments,

- a digital image analysis for the measurement of strain distributions,

- a mechanical modelling to predict both the PET behaviour and the impact of PET reprocessing on its mechanical properties.

Details on the experimental testing are given in Materials and Procedures. The DIC procedure is briefly presented. The stress and strain distributions resulting from the uniaxial loading tensile tests for two sample geometries (normalised and hourglass specimens) are compared 
(Macroscopic Behaviour and Mesoscopic Behaviour Striction Instability). An initial analysis of the impact of successive extrusions on PET is subsequently achieved. To quantify this material's degradation, a phenomenological model reproducing the experimental behaviour is used. Analytical modelling and finite element model updating (FEMU) coupled with DIC are used to define a set of constitutive parameters for each extruded sample (Constitutive Model).

\section{Materials and Procedures}

\section{Materials}

Post-consumer PET (labelled $R 1$ ) was obtained by washing and milling bottles of various French trademarks. Scraps of PET were supplied by SOREPLA Recycling Center (Neufchateau, France). A Differential Scanning Calorimeter (Perkin Elmer Diamond DSC, Walthman, MA, USA) was used to obtain thermographs of samples from which the percentage of crystallinity can be deduced. Solution viscosity measurements were carried out in a viscosimeter Tuan-Fuoss. The intrinsic viscosity was obtained by extrapolation using the Huggins equation. The main PET characteristics are the following: intrinsic viscosity $=0.76 \mathrm{dL} \mathrm{g}^{-1}$, crystallinity $=$ $33 \%$, density $=1.41$, mean molecular weight $=$ $63 \mathrm{~kg} \mathrm{~mol}^{-1}$. The extrusion was performed with a singlescrew extruder (Compact; Fairex, Le Bourget, France) at $260{ }^{\circ} \mathrm{C}$ with a screw rate of $80 \mathrm{rpm}$. The PET scraps were dried for $15 \mathrm{~h}$ at $120^{\circ} \mathrm{C}$ in an oven to reduce the moisture content to $<0.02 \%$. ISO $5272-1$-A samples were obtained by injection. PET was successively extruded 2, 3 and 4 times; the associated samples were labelled $R 2, R 3$ and $R 4$, respectively. It was observed [23] that the content of carboxyl endgroups increases with the number of processing cycles, varying from $79 \mathrm{eq} / 10^{6} \mathrm{~g}(R 2)$ to $106 \mathrm{eq} / 10^{6} \mathrm{~g}(R 4)$ (Table 1$)$. The degree of crystallinity decreases after the second processing cycle $(33 \%[R 1]$ to $14 \%[R 2])$ and subsequently remains stable $(18 \%[R 3], 11 \%[R 4])$ (standard deviation of the results $= \pm 5 \%$ ). This behaviour is due to thermal and/or thermo-oxidative chain scissions that induce an increase in carboxyl end-groups and a decrease in the mean molecular weight [24]. These preliminary results indicate that the number of times PET is reprocessed has a considerable impact on its molecular distribution and structure during extrusion, that is, on its final microstructure [25].

Uniaxial tensile tests were performed on two types of geometries. The first geometry corresponds to Standard ISO-5272-1-A; a curved central profile is realised on some of these samples to localise necking (Figure 1). This latter hourglass geometry prevents fractures from occurring in

Table I: Crystallinity ratio and concentration of carboxyl endgroups for reprocessed polyethylene terephthalate $(R 2, R 3, R 4)$

\begin{tabular}{lll}
\hline & $\begin{array}{l}\text { Crystallinity degree } \\
\%( \pm 5 \%)\end{array}$ & $\begin{array}{l}\text { Carboxyl end-group concentration } \\
\text { Eq/ } 10^{6} \mathrm{~g}\left( \pm 5 \mathrm{eq} / 10^{6} \mathrm{~g}\right)\end{array}$ \\
\hline$R 1$ & 33 & 47 \\
$R 2$ & 14 & 79 \\
$R 3$ & 18 & 96 \\
$R 4$ & 11 & 106 \\
\hline
\end{tabular}

(A)

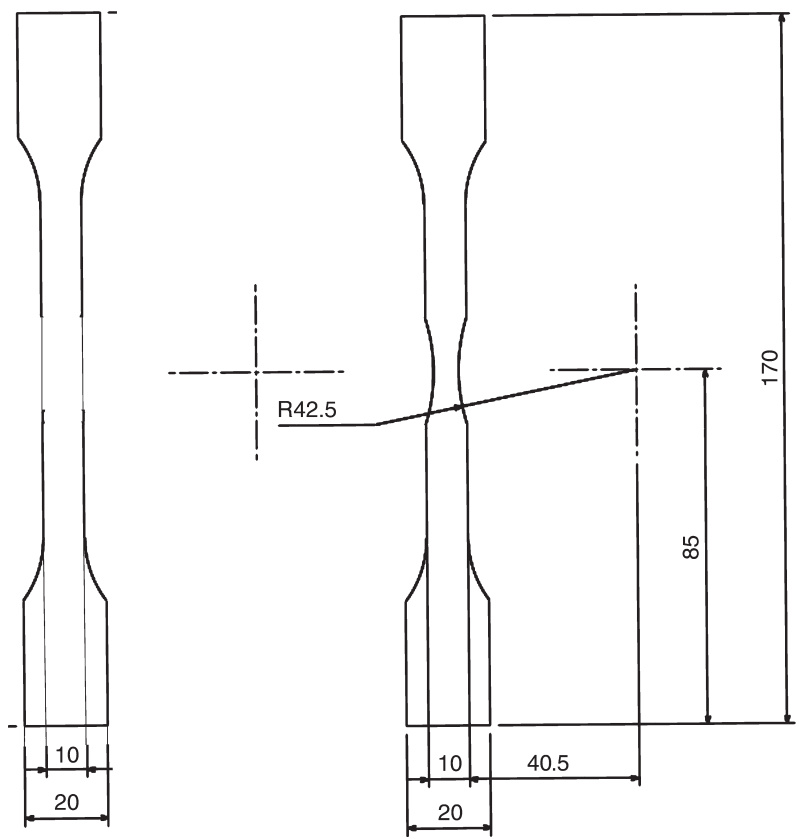

Figure I: Geometry of the standard iso 5272-1-A (A) and the hourglass specimen (B) (quotations in $\mathrm{mm}, R$ radius of curvature), thickness $4 \mathrm{~mm}$

the vicinity of the jaws. Thus, the creation of a curved section induces stress heterogeneities throughout the section. A finite element optimisation has been performed to determine the radius of curvature, chosen here equal to $42.5 \mathrm{~mm}$, that allows a stress gradient along the minimal section of $5 \% \mathrm{MPa}$. The constant cross-section specimen was used for a macro-homogeneous study, whereas the hourglass sample enabled a necking study in the area of minimum cross-section.

\section{Tensile tests and photomechanics}

The uniaxial tensile tests were performed using a Zwick Z010 universal test setup with two different cross-head speeds that are equivalent to a strain speed of $1.3 \times 10^{-4} \mathrm{~s}^{-1}$ and $8.3 \times 10^{-3} \mathrm{~s}^{-1}$ and a gauge size of $110 \mathrm{~mm}$. The specimens were clamped between the two jaws of the tensile test device and were subjected to either monotonic or nonmonotonic loadings. The latter case refers to two loadingunloading cycles both before and after the peak stress. The nominal stress $\left(\sigma_{N y}\right)$ is defined as the ratio between the uniaxial force recorded by the test equipment $\left(F_{y}\right)$ and the initial cross-sectional area of the sample $\left(S_{0}\right)$ as described in Equation (1):

$\sigma_{N} y=F_{y} / S_{0}$.

During the tensile tests, the displacement of points within a specific surface area on a specimen, known as the Zone of Interest (ZOI), was also continuously measured. A camera CCD (Redlake Megaplus II) was placed in front of the specimen, and the lens axis of the camera was kept perpendicular to the surface of the sample. Measurement of the two-dimensional in-plane displacements was performed using correlation calculations 

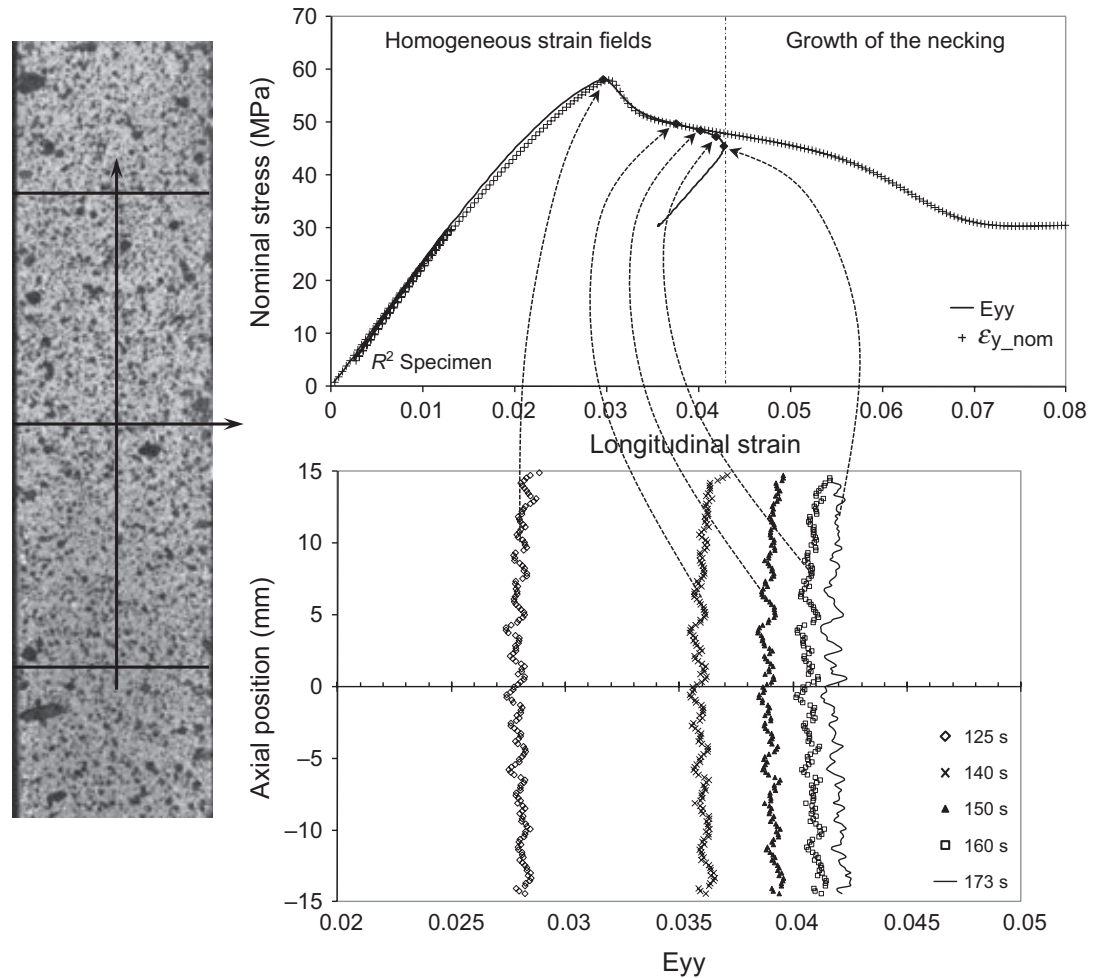

Figure 2: Nominal stress-strains curve $\left(\sigma_{N y}-\varepsilon_{y}\right)\left(\sigma_{N y}-\mathbf{E}_{\gamma}\right)$ : strain profiles of longitudinal Lagrangian strain $\left(\mathbf{E}_{\gamma}\right)$ evaluated by DIC on the vertical axis of symmetry ( $R 2$ specimen). DIC, digital image correlation

involving digital image processing of the image sequences acquired during the test (home-made CinEMA $^{\circledR}$ software) $[26,27]$.

Image correlation or 'map-matching' techniques, widely used to compare two signals, are part of an optical method used to measure the displacement fields on a surface sample by comparing pictures acquired at different states of strain. Before the test, the inspected sample surface was spray-painted with a thin layer of paint to give it an artificial granular appearance that is similar to speckle (see image signature in Figure 2). With this image signature, a subset of pixels must be statistically representative of the light intensity distribution of a material point located at the centre of the subset. Extended to the whole ZOI, the correlation calculations return the kinematics of each digital pattern in the pre-defined virtual mesh. Next, the gauge length and the two-dimensional digital extensometer have to be defined. Knowing the sample width $(10 \mathrm{~mm}-$ ISO527) and minimising edge effects with the correlation calculation, a gauge-length unit of $9 \mathrm{~mm}$ was used for macroscopic measurements.

Strains are directly evaluated by derivative of the displacements field obtained at the neighbouring points and the components of the in-plane Green-Lagrange strain tensor, $\mathbf{E}$, can be expressed by the formula:

$E=1 / 2\left(F^{\mathrm{T}} F-I\right), F=\frac{\partial x(X)}{\partial X}, \quad u(X)=x(X)-X$

where $x(X)$ maps the initial coordinate, $X$, onto the current coordinate, $x$, of a material particle and $u$ is the displacement vector. Capital boldface letters refer to second-order tensors.
Let $\boldsymbol{y}$ be the tensile direction, $\mathbf{z}$ be the out-of-plane direction and $\boldsymbol{x}-\boldsymbol{y}$ be the planar surface such that $(\boldsymbol{x}, \boldsymbol{y}, \mathbf{z})$ is an orthonormal basis; $u_{x}, u_{y}, u_{z}$ refer to the projection of the displacement vector according to $\boldsymbol{x}, \boldsymbol{y}$ and $\boldsymbol{z}$. The components of the 2D Green-Lagrange strain tensor, denoted by $\mathbf{E}_{x x}, \mathbf{E}_{y y}, \mathbf{E}_{x y}$, are thus evaluated. A further verification will validate the lack of shearing (see Tensile Tests on Standard Specimens on the experimental part $)\left(\mathbf{E}_{x y} \approx 0\right.$ ) and for the sake of simplicity, $\mathbf{E}_{x x}$ and $\mathbf{E}_{y y}$ will be denoted by $\mathbf{E}_{x}$ and $\mathbf{E}_{y}$ because $(\boldsymbol{x}, \boldsymbol{y}, \mathbf{z})$ is a principal basis. Although the transverse isotropy assumption is widely used to extend the two-dimensional measurement to the entire volume loaded in tension, it is also questionable: this hypothesis was also validated by some authors especially on a highdensity polyethylene (HDPE) or a polycarbonate (PC) specimen [28, 29]. They have made three-dimensional optical measurements and have showed on tensile specimens that until about 50 and 30\% of nominal strain for HDPE and PC respectively, transverse isotropy assumption is satisfied. Beyond this strain level, the specimen contracts more in the thinner direction than it does in the wider direction, and three-dimensional measurements are required to calculate accurately the true stress and the volumetric strain. These studies thus show that the transverse anisotropy depends on both the rectangular section and the nature of the material. In the case of elastomeric material, this hypothesis has been validated until 3\% of axial stretch on $30 \times 4 \times 2 \mathrm{~mm}^{3}$ shape sample [30]. Moreover, it is interesting to notice that the transverse isotropy assumption is also validated upon the occurrence of necking. 
So for this study, volumetric strain was calculated using front-view data only and assuming transverse isotropy. It is therefore possible, to record the volume strain, $\mathbf{E}_{V}$, up to large deformations, where $\mathbf{E}_{V}$ is defined as

$\mathrm{E}_{V}=\frac{\Delta V}{V_{0}}=\lambda_{x}^{2} \lambda_{y}-1 \quad$ where $\quad \lambda_{i}=\sqrt{2 \mathrm{E}_{i}+1}, i=x, y$

$V$ is the current volume, $V_{0}$ the original volume and $\lambda_{x}$ (or y) are the in-plane principal stretch ratios in the $\boldsymbol{x}$ (or $\boldsymbol{y}$ ) direction.

The macroscopic true stress can be therefore calculated as $\sigma_{\text {true }}=F_{y} / \lambda_{x} \lambda_{z} S_{0}$.

The experimental strain, $\varepsilon_{y}$, determined from the displacements of the clamps, can also be continuously measured and compared to $\mathbf{E}_{y}$ during the test run.

\section{Macroscopic Behaviour}

Tensile tests on standard specimens

Digital image correlation is achieved on a regular mesh of 9 by $9 \mathrm{~mm}^{2}$ on the standard shape specimen and enables the identification of homogeneous in-plane Lagrange deformation tensor components: $\mathbf{E}_{x}, \mathbf{E}_{y}$ in the principal basis. These latter dimensions determine the gauge length of the twodimensional digital extensometer. The results of the comparison between the Lagrangian strain evaluated by DIC $\left(\mathbf{E}_{y}\right)$ and the nominal strain $\left(\varepsilon_{y}\right)$ show a similar evolution until $4.2 \%$ of nominal strain (Figure 2 ). It should be noted that although results are deduced from two different gauge sizes (110 $\mathrm{mm}$ for the jaw displacements and $9 \mathrm{~mm}$ for the DIC), they are perfectly reproducible until this level of strain. After that point, the stress and strain deduced from DIC decrease, whereas the nominal strain, $\varepsilon_{y}$, still increases. The macroscopic study is focused on the homogeneous behaviour of the sample (before the onset of the necking). For this specimen, the necking began in the jaw vicinity and induced the diminution of load and the lagrangian strain $\left(\mathbf{E}_{y}\right)$ while nominal strain $\left(\varepsilon_{y}\right)$ still increases. In the interesting zone, at the central part of the specimen, the deformation profiles, evaluated by DIC and associated with a 2-mm gage length, show the strain homogeneity upon the growth of the necking (Figure 2). Another finding regarding the behaviour curve is that the mechanical behaviour stays homogeneous beyond the stress peak: therefore, the decrease of the state of stress following the stress peak is associated with softening of the material. The decrease of the nominal stress when the signals corresponding to different lengths of separate gauge is associated with the onset of necking instability. In the remainder of this section, the results presented correspond to a homogeneous field response, before the onset of necking phenomenon. The localisation phenomena will be fully studied specifically in Mesoscopic Behaviour - Striction Instability of this paper.

During the homogeneous response of the material and until striction phenomenon, out-of-plane displacement has not impact on in-plane strain measurement. An LVDT sensor located in contact with the specimen leads to an out-of-plane motion $<8 / 10 \mathrm{~mm}$ which induces an in-planestrain error $<10^{-3}$. This outcome is the result of the choice of magnification (30 $\mu \mathrm{m}$ per pixel) which represents a compromise between high spatial resolution and low effect of out-of-plane motion on the strain in-plane. Further information on these calibration methods is provided in the reference [9].

Stress-strain curves, in association with their deformation-time curves, are shown in Figures 3 and 4 for the twice-reprocessed recycled PET (R2) from which the loading-unloading cycles are performed before (Figure 3 ) and after the yield point (Figure 4). First, the lack of macroscopic shearing $\left(\mathbf{E}_{x y}<1.3510^{-4}\right.$ measured by DIC validates both the type of test in tension and the similarity between the both coordinate systems associated with the camera and to the loading (Figures $3 \mathrm{~A}$ and $4 \mathrm{~A}$ ). The tensile stressstrain curve shows a stress maximum (peak stress) followed by stress softening. These stages of the deformation process can qualitatively be related to the microscopic deformation mechanisms of the semi-crystalline polymer. First, elongation of the amorphous tie chains occurs; second, slip and tilting of crystalline lamellar chains occurs; and third, the orientation of crystal blocks occurs [31].

The first tensile-test cycle (Figure 3) indicates the range of elastic deformation (elastic loading and unloading before $2 \%$ of strain) followed by the peak stress. In the second cycle performed after the peak stress (Figure 4), a return to zero stress produces a sizeable plastic deformation. In addition, the slope of these both curves remains constant between loading and unloading, thereby confirming an elastic behaviour response of the material during unloading steps.
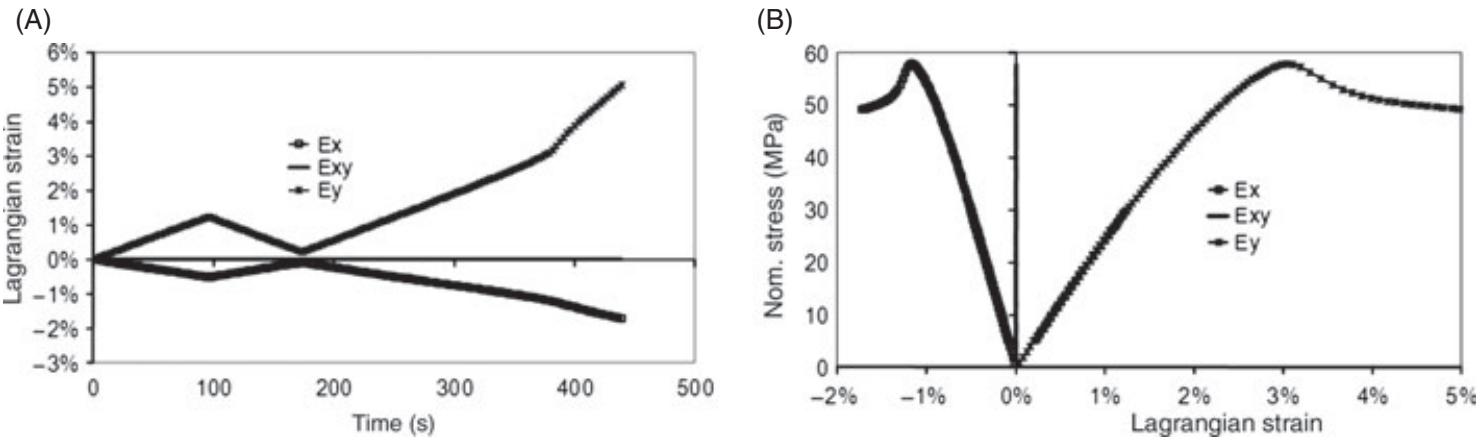

Figure 3: Cyclic loading before the peak stress: (A) Lagrangian strains $\left(\mathbf{E}_{x}, \mathbf{E}_{y}, \mathbf{E}_{x y}\right)$ versus time for the $R 2$ specimen (B) Nominal stress $\left(\sigma_{N y}\right)-$ Lagrangian strains $\left(\mathbf{E}_{x}, \mathbf{E}_{y}, \mathbf{E}_{x y}\right)$ curve for the $R 2$ specimen 
(A)

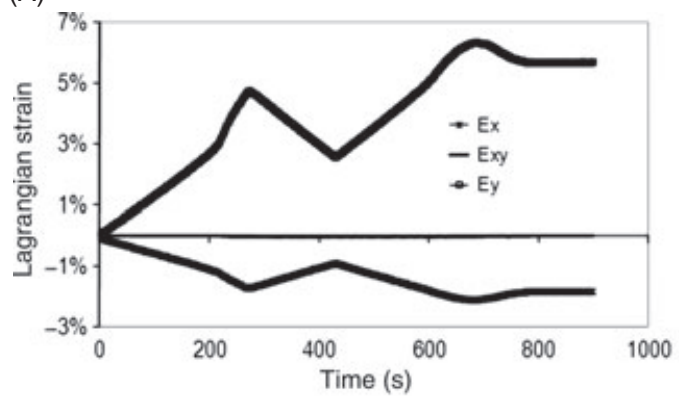

(B)

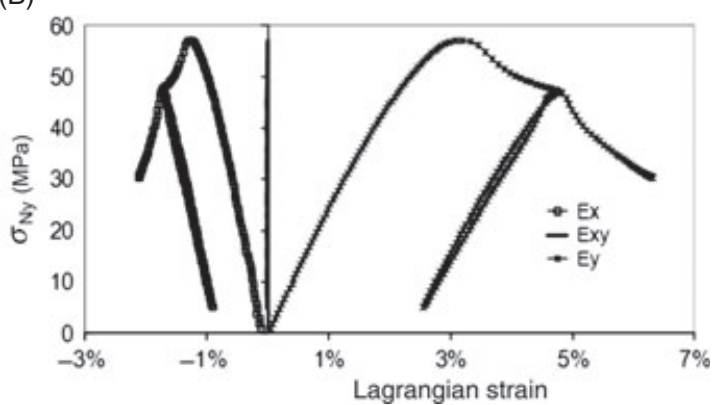

Figure 4: Cyclic loading after the peak stress: (A) Lagrangian strains $\left(\mathbf{E}_{x}, \mathbf{E}_{y}, \mathbf{E}_{x y}\right)$ versus time for the $R 2$ specimen (B) Nominal stress $\left(\sigma_{N y}\right)-$ Lagrangian strains $\left(\mathbf{E}_{x}, \mathbf{E}_{y}, \mathbf{E}_{x y}\right)$ curve for the $R 2$ specimen

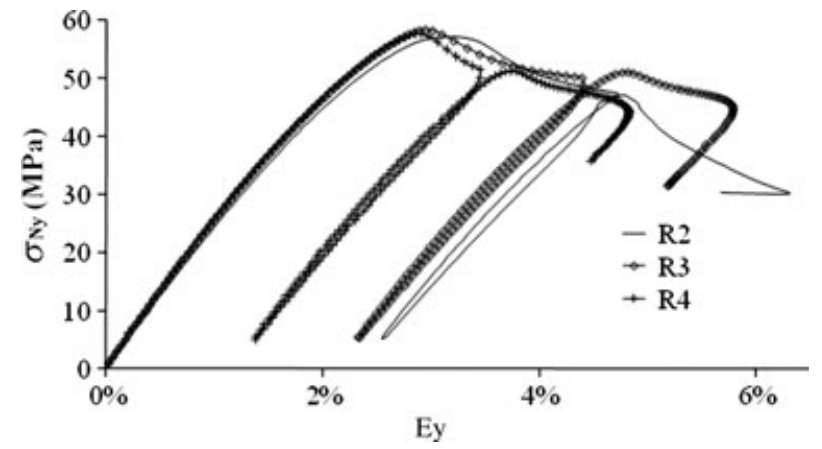

Figure 5: Nominal stress $\left(\sigma_{N y}\right)$ - strain $\left(\mathbf{E}_{y}\right)$ curve as a function of PET reprocessing $(R 2, R 3, R 4)$. PET, polyethylene terephthalate

Figure 5 shows the stress-strain curves for $R 2, R 3$ and $R 4$. Apparently, before the onset of the necking (homogeneous mechanical response of the material), the mechanical behaviour is not influenced by reprocessing. Constitutive Model relates specifically the study of necking for which further local analyses are necessary to assess the common assumption that reprocessing induces chemical, and thus, mechanical damage on the material.

\section{Influence of strain rate}

Tensile tests were performed at two loading speeds ( 1 and $10 \mathrm{~mm} \mathrm{~min}^{-1}$ ) to highlight the effect of loading speed on the mechanical behaviour of PET. Figure 6 presents the uniaxial stress-strain curve of PET performed at various strain rates. The first observation is that the yield stress slightly increases with an increasing strain rate. Nevertheless, for the sake of simplicity, the time dependence was neglected in this study. Several authors [15] take into account this time dependence through a two-phase representation of semi-crystalline polymers at a mesoscopic level under large strain.

\section{Volume strain}

Digital image correlation enables the evaluation of volume strain using the transverse isotropy assumption (Equation 3). The DIC results indicate a similar increase in the volume strain for all specimens (Figure 7A). Under the assumption of small deformation, a simplified elastic-analysis leads to the elastic volume strain [Figure 7B, where $\mathbf{E}_{V_{-} \exp }$ is the experimental volume strain as defined in Equation (3)]

$E_{V_{-} \text {an }}=\frac{1-v}{E} \sigma_{N y}$

where $\mathbf{E}$ and $v$ are, respectively, the Young's modulus (deduced from the initial slope of the stress/strain curve) and the Poisson's ratio.

First, with the specimen below $2 \%$ of strain, in the elastic stage, the elastic assumption enables the determination of volumetric changes $\left(E_{V} \approx E_{V \_a n}\right)$. For a level of strains above $2 \%$, the volumetric strain increases monotonically; bleaching of the sample under uniaxial tension is commonly observed and is associated with crazing, cavitation and significant dilatation. This phenomenon, already observed by G'Sell et al. [8], explains the development of the damage processes before the peak stress.
(A)

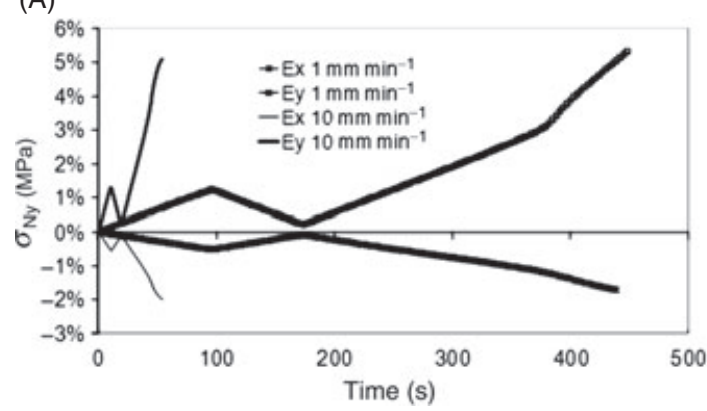

(B)

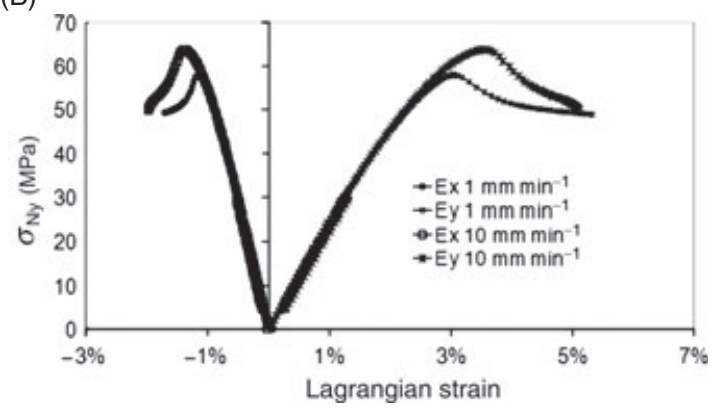

Figure 6: (A) Strains $\left(\mathbf{E}_{x}, \mathbf{E}_{y}\right)$ versus time (B) Nominal stress $\left(\sigma_{N y}\right)-$ strains $\left(\mathbf{E}_{x}, \mathbf{E}_{y}\right)$ curve at two loading speeds $\left(1 \mathrm{and} 10 \mathrm{~mm} \mathrm{~min}^{-1}\right)(R 2$ specimen) 

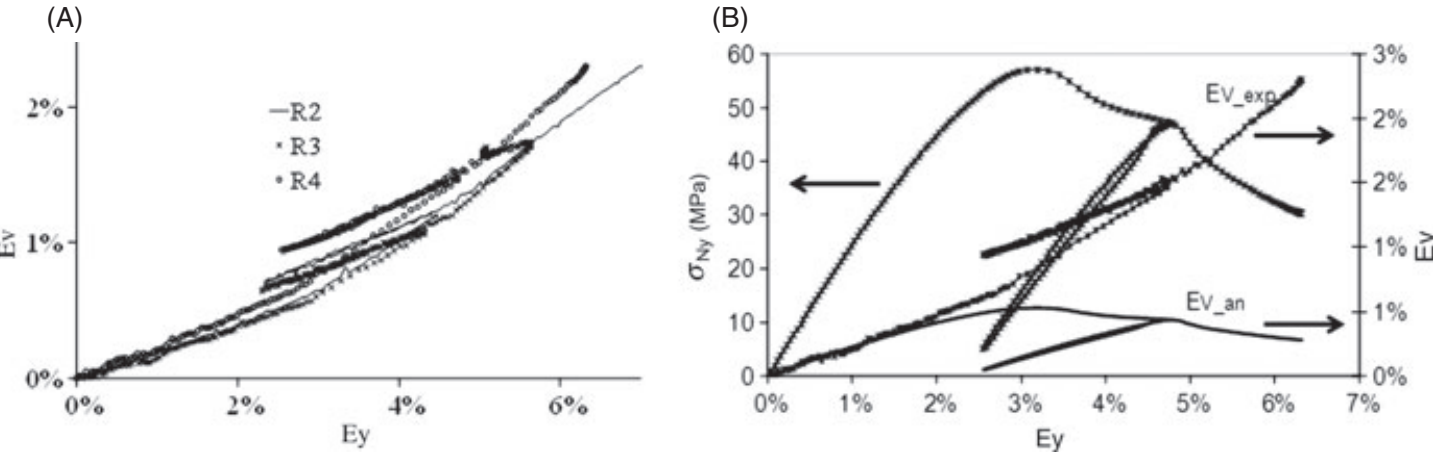

Figure 7: (A) Volumetric strain $\left(\mathbf{E}_{V}\right)$ versus Lagrangian strain $\left(\mathbf{E}_{y}\right)(R 2, R 3$ and $R 4)$ (B) Analytical $\left(\boldsymbol{E}_{V \_ \text {an }}\right)$ and experimental volumetric strain $\left(\mathbf{E}_{V \_\underline{\exp }}\right)$ versus Lagrangian strain $\left(\mathbf{E}_{V}\right)$
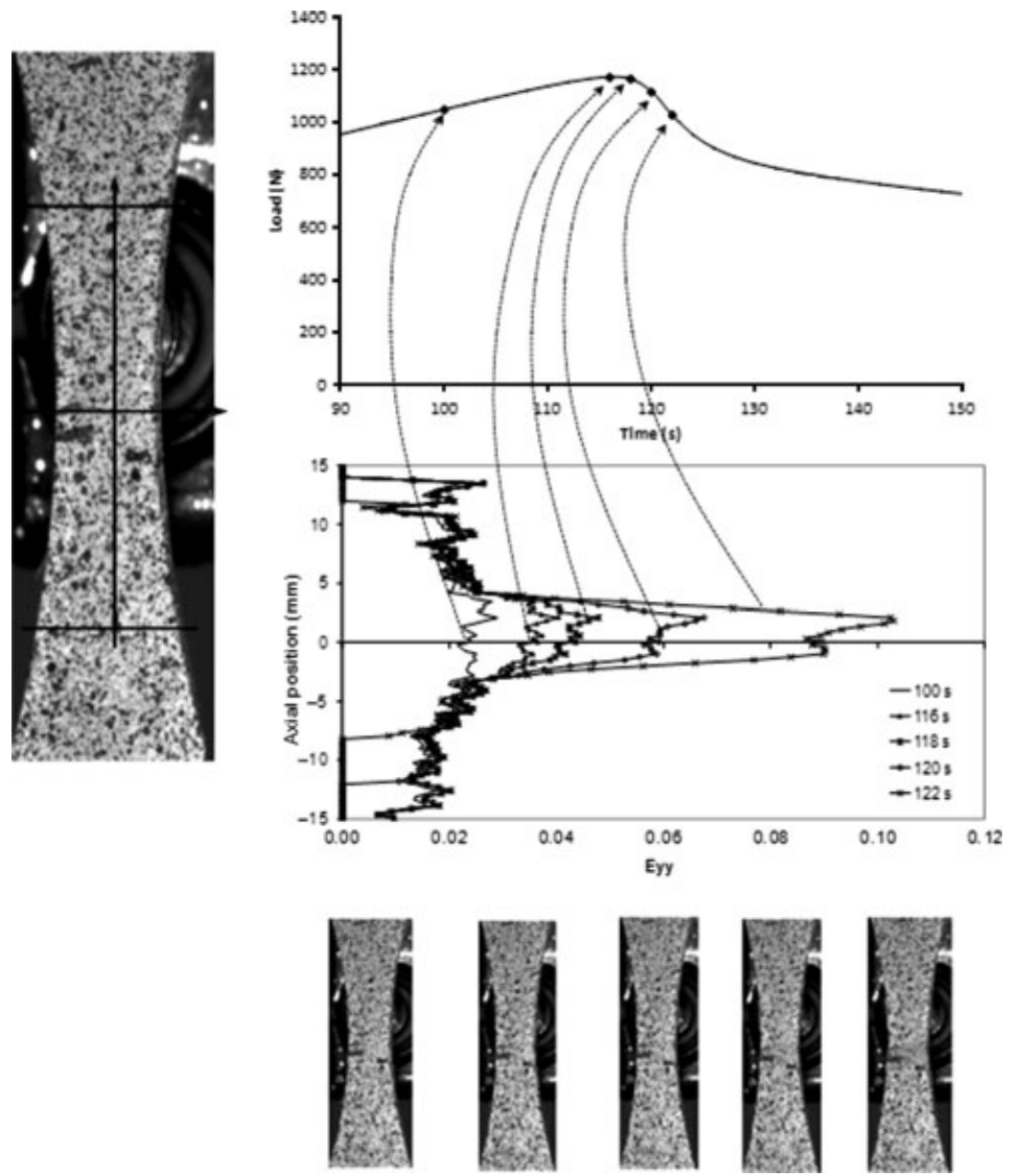

Figure 8: Geometric instability due to necking: load versus time, strain profiles of longitudinal Lagrangian strain ( $\left.\mathbf{E}_{y}\right)$ evaluated by DIC versus position along a vertical axis ( $R 2$ specimen). DIC, digital image correlation

This behaviour is significantly different than that expected from the commonly accepted isochoric assumption, thereby proving that the strain-dependant elastic assumption is necessary, even at very low strain. Zaïri et al. [16] studied the behaviour of a two-phase material and described its volume variation with the void-growth concept under the assumption of transverse isotropy. In other studies [24, 25], the authors attribute volume change to the compressibility of the amorphous phase.
The purpose of the next section is to study the necking instability.

\section{Mesoscopic Behaviour - Striction Instability}

Tensile tests on curved specimens - DIC

Two-dimensional fields of in-plane displacements were measured according to the digital processing as mentioned in Tensile Tests and Photomechanics. The curved geometry induces necking localisation in the zone of interest. Figure 8 
shows the reference image of an $R 2$ curved specimen, the evolution of load and axial lagrangian strain as a function of axial vertical position at several level of load. The deformation profiles have been evaluated by DIC associated with a 2-mm gage length. At a low level of strain (at a step before the stress peak), macroscopic behaviour can be considered as homogeneous: only a gradient associated with the progressive reduction of the resistive section is observed. After this time, strain profiles reflect the onset of necking instability. This observation is in accordance with Tensile Tests on Standard Specimens in which homogeneous behaviour has been considered until $4.2 \%$. In this case, the geometry of the sample with a constant section must delay necking. For the localisation test, the curved profiles of the sample generate a minimum section which is the weak point where necking can grow between 2 and $3 \%$ of strain. It is important to note that the in-plane strain presented here is essentially qualitative and informs us about the phenomenology of the necking instability: in the necking zone, the specimen surface is both no longer plane and no longer parallel to the lens axis of the camera. The interpretation of the tensile tests performed on curved specimens necessitates mechanical modelling based on the Finite Element Method. This modelling presented in Constitutive Model integrates both the in-plane displacement fields from DIC which constitute a part of the necessary information. This modelling associated with optical-strain measurements provides information about the damaged area and enables local-strain analysis during tensile tests.

\section{Damaging mechanisms - observation by SEM}

To complete these observations, uniaxial-deformation tests were performed in a scanning electron microscope (SEM) using a tensile stage. Microstructure evolution was examined on cryofractured samples $4 \times 1 \mathrm{~mm}$ approximatively in size. These thin foils were cut parallel to the direction of the applied stress and polished for a short time (30-60 s). Tensile deformation was performed inside the SEM (with the SEM accelerating voltage set at $15 \mathrm{kV}$ ) using a displacement control. These in-situ experiments were recorded on DV-Cam (20 frames per second). Thin sections were tested at a constant tensile strain rate of $5.10^{-4} \mathrm{~s}^{-1}$ and at room temperature. Typical selected images are shown in Figure $9 \mathrm{~A}-\mathrm{C}$ and reveal damage mechanism related to surface cavitation. These cavities are mainly responsible for the mechanical softening behaviour observed under tension [6] (see Volume Strain).

\section{Constitutive Model}

Phenomenological modelling of the mechanical behaviour Sequenced tensile tests confirm the coexistence between two complementary phenomena: plasticity (with a permanent deformation) and volumetric dilatation that plasticity is unable to describe. To address both of these phenomena, a classical elastoplastic law associated with the strain-dependant elastic components in the framework of large strain was employed. In [29] authors model PC volumetric behaviour with plastic relaxation and cavitation.

Confining our attention to isothermal situations, the material model is based on the multiplicative split of the deformation gradient, $\mathbf{F}$, into elastic, $\mathbf{F}_{e}$, and plastic, $\mathbf{F}_{p}$, parts $\mathbf{F}=\mathbf{F}_{e} \mathbf{F}_{p}$.

The Helmholtz free energy is assumed to be defined as follows:

$\psi=\psi_{e}\left(\mathrm{~F}_{e} \mathrm{~F}_{e}^{T}, p\right)+\psi_{p}(p)$

where $\rho \psi_{e}=\frac{1}{2} C(p)\left(B_{e}-1\right)^{2}$ is an isotropic function of the elastic left-tensor of Cauchy Green, $\mathrm{B}_{e}=\mathrm{F}_{e} \mathrm{~F}_{e}^{T}, \psi_{p}$ is the part of the free energy associated with plastic hardening/softening phenomena in the material, as detailed later, $p$ is the accumulated plastic strain and $\mathbf{C}$ is the stiffness matrix (a fourth-order tensor).

Under the assumption of homogeneity and isotropy, the elastic stiffness matrix depends therefore upon $\mathbf{E}(p)$ and $v(p)$ which are respectively, the Young's modulus and the Poisson's ratio, both depending on the accumulated plastic deformation, $p$.

In the present work, a continuous damage mechanics model was applied to reproduce the volume variation. Damage evolution is driven only by accumulated plastic strain [32]. In [33], authors have modelled volumetric variation of an extruded PEHD material through evolution of both Young modulus and Poisson coefficient [5 (2) parameters enable a description of Young modulus (Poisson ratio)]. Note that in Figure 7A, the volumetric variation follows a bilinear stage evolution, likewise for all the specimens. In fact, despite the observed microstructural changes, the elastic parameters did not change with
(A)

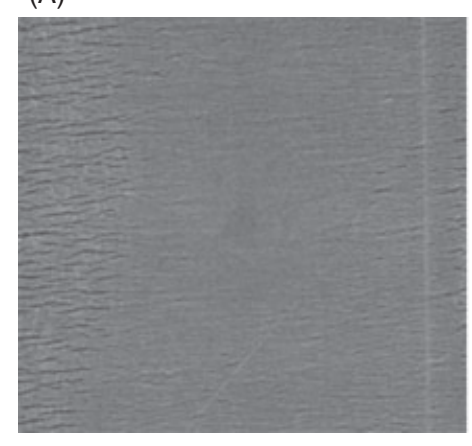

(B)

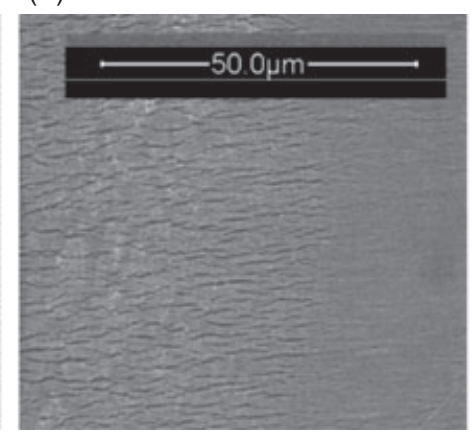

(C)

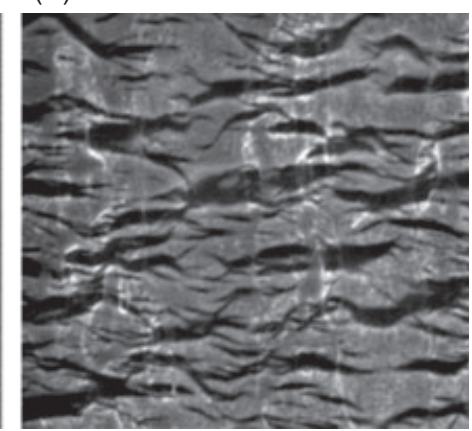

Figure 9: SEM micrograph of $R 2$ taken from the same sample area at three different nominal strain levels: (A) $\varepsilon_{y}=2.5 \%$ (B) $\varepsilon_{y}=2.8 \%$ (C) $\varepsilon_{y}=3.7 \%$ 
reprocessing (Table 1). Two steady negative exponentials were combined. Each of these exponentials contributes to the decrease and the stabilisation of the elastic properties. The evolution of the elastic parameters is described as follows:

$E=\bar{E}\left[m_{1} \exp \left(-\alpha_{1} p\right)+m_{2} \exp \left(-\alpha_{2} p\right)\right], m_{1}+m_{2}=1, E \in[\bar{E} ; 0]$

$v=\bar{v}\left[m_{1} \exp \left(-\alpha_{1} p\right)+m_{2} \exp \left(-\alpha_{2} p\right)\right], m_{1}+m_{2}=1, v \in[\bar{v} ; 0]$

The dissipation inequality is fulfilled, and the nominal Cauchy stress tensor (and thus $\sigma_{N x}, \sigma_{N y}, \sigma_{N x y}$ ) is

$\sigma=2 \rho \frac{\partial \psi_{e}}{\partial B_{e}} B_{e}, \quad R=\rho \frac{\partial \psi_{e}}{\partial p}+\rho \frac{\partial \psi_{p}}{\partial p}=R_{e}+R_{p}$

This equation leads to the evolution equations:

$\mathrm{D}_{p}=d \lambda \frac{\partial f}{\partial \tau}, \quad \dot{p}=-d \lambda \frac{\partial f}{\partial R}$,

where $\tau$ is the deviatoric part of the Cauchy stress, and $\lambda$ is obtained from the constituency condition, $\mathrm{d} f=0$.

In this equation, the isotropic-yield function of Von Mises is performed:

$$
f=\sqrt{\tau: \tau}-R_{p}
$$

with

$R_{p}=R_{0}+Q_{1}\left(1-e^{-b_{1} p}\right)+Q_{2}\left(1-e^{-b_{2} p}\right), Q_{1}>0, Q_{2}<0, b_{1}, b_{2}>0$

where $R_{p}$ is the drag stress such that $\dot{p}=d \lambda$. A nonlinear isotropic hardening that yields a two-term saturation evolution was chosen. This model reproduces the classical polymer strain-stress curve, that is, a drop of stress after the yield stress and an asymptotic softening stage.

The intrinsic dissipation can be written as follows:

$D=\left[\left(\sqrt{\tau: \tau}-R_{p}\right)-\left(\frac{1}{2} \frac{\partial C(p)}{\partial p}\left(B_{e}-1\right)^{2}\right)\right] \dot{p}$

Owing to the non-negativity of the plastic multiplier, $d \lambda$, the first component of the dissipation fulfilled the condition that it be a positive quantity. Moreover, because $\alpha_{1}, \alpha_{2}$, $m_{1}, m_{2}$ are assumed to be positive, and $\frac{\partial E(p)}{\partial p} \leq 0$ and $\frac{\partial v(p)}{\partial p} \leq 0$, the second term in the bracket is thus positive.

The proposed model involves four elastic constants $\left(\alpha_{1}\right.$, $\alpha_{2}, m_{1}, m_{2}$ ) related to the volume variation and five parameters for the plasticity $\left(R_{0}, Q_{1}, b_{1}, Q_{2}, b_{2}\right)$ reproducing the softening and unloading behaviour. Let us denote by $\boldsymbol{\theta}=\left[E_{0}, v_{0}, m_{1}, \alpha_{1}, m_{2}, \alpha_{2}, R_{0}, Q_{1}, b_{1}, Q_{2}, b_{2}\right]$ this set of constitutive parameters.

\section{Identification of the parameters of the model Identification on the basis of homogeneous tests}

A first identification is obtained from the macro-homogeneous results of Macroscopic Behaviour. From both the full Lagrange strain tensor identified by DIC and the nominal stresses, the material behaviour can be determined. From the previous Equations (6-11) and with the knowledge of the elastic left Cauchy Green tensor, the in-plane nominal stress tensor is determined as a function of $\boldsymbol{\theta}$. This stress evaluation is performed in Matlab ${ }^{\circledR}$. Let us denote $\boldsymbol{\theta}^{*}$ to be

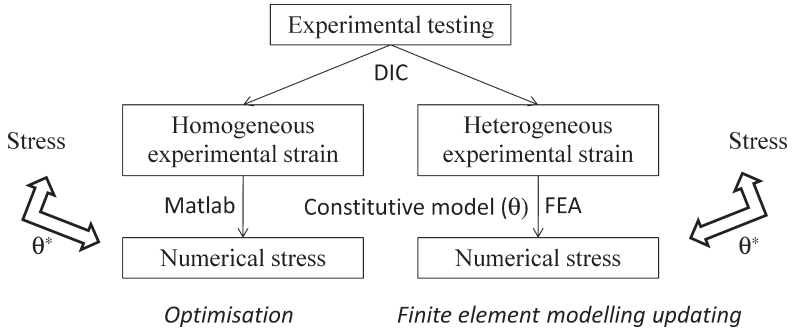

(A)

(B)

Figure 10: Identification procedure

the set of constitutive parameters that minimise both $J_{x}=\sigma_{N x}(\boldsymbol{\theta})$ (tensile-loading transverse stress is not expected) and $J_{y}=\sigma_{N y}(\boldsymbol{\theta})-\sigma_{N y}$ (see part (a) in Figure 10).

The results of the macro-homogeneous identification process are listed in Table 2.

Consequently, as a first interpretation, reprocessing seems unlikely to affect neither the initial elastic parameters nor their strain-dependant behaviours, while the values in Table 1 suggest that micro-structural evolution occurs. The corresponding stress-time curves are shown in Figure 11 for the $R 2$ specimen, with unloading occurring before and after the peak stress. These figures demonstrate that the model efficiency, particularly for plastic strains, is in accordance with the deterioration of elastic properties due to damage (Figure 11B). Nevertheless, discrepancies after the second loading cycle are observed.

In Figure 12A, one can follow the associated evolution of the elastic parameters as a function of axial strain for the fitted parameters ( $R 2$ formulation). The Young's modulus and Poisson's ratio decrease from $2 \%$ of strain to reproduce the volumetric variation (Figure 7A). The accumulated plastic strain increases simultaneously and remains constant during unloading (Figure 12B).

Even after the fourth cycle of reprocessing, there is no significant change in the elastic properties of the material, although several authors observed an increase of PET stiffness during recycling processes [34-36]. In a previous work [23], large disparities in the rheological (and thus mechanical) behaviours of PET versus reprocessing cycles were presented. In fact, polymer thermal-oxidation induces chain scissions in 'well-oxygenated' extruder zones, whereas chain couplings predominate in 'low-oxygenated' extruder zones. Consequently, the material behaviour is closely related to the extruder geometry and size. Nevertheless, the literature shows that reprocessing leads to structural changes, such as the formation of hydroxyl- and carbonyl-groups, chain scissions or extensions, branching

Table 2: Materials parameters (elastic and plastic) fitted from the standardised test for reprocessed polyethylene terephthalate $(R 2$, $R 3, R 4)$

\begin{tabular}{llllllllllll}
\hline & $\bar{E}$ & $\bar{v}$ & $m_{1}$ & $m_{1}$ & $\alpha_{1}$ & $\alpha_{2}$ & $R_{0}$ & $Q_{1}$ & $b_{1}$ & $Q_{2}$ & $b_{2}$ \\
\hline$R 2$ & 2485 & 0.14 & 0.8 & 0.2 & 0.7 & 0.1 & 42 & 30 & 350 & -39 & 40 \\
$R 3$ & 2580 & 0.16 & 0.8 & 0.2 & 0.7 & 0.1 & 43 & 30 & 350 & -39 & 40 \\
$R 4$ & 2570 & 0.17 & 0.8 & 0.2 & 0.7 & 0.1 & 42 & 30 & 350 & -50 & 38 \\
\hline
\end{tabular}


(A)

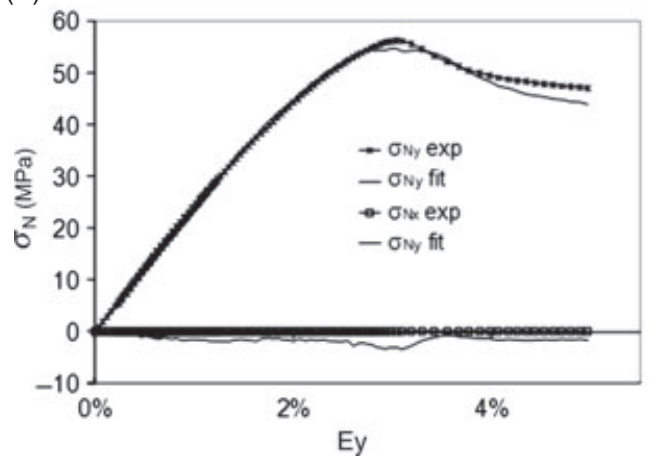

(B)

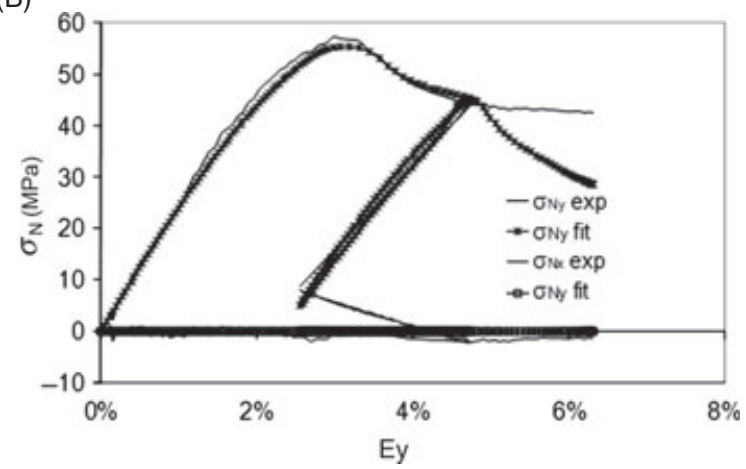

Figure I I: Macro-homogeneous identification: nominal stresses $\left(\sigma_{N x}, \sigma_{N y}\right)$ versus Lagrangian strain ( $\left.\mathbf{E}_{y}\right)$ for the $R 2$ specimen (A) with unloading before the yield point (B) with unloading after the yield point

(A)

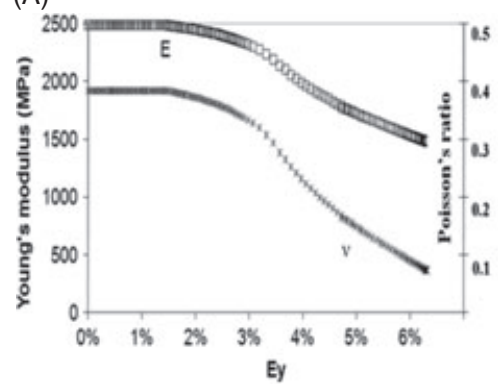

(B)

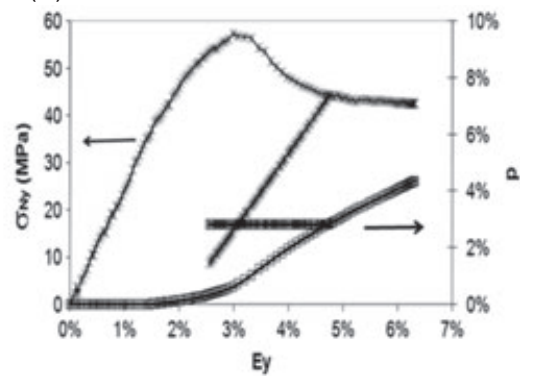

Figure I2: (A) Young's modulus and Poisson's ratio versus Lagrangian strain $\left(\mathbf{E}_{y}\right)(R 2, R 3, R 4)$ (B) Evolution of the accumulated plastic strain $(p)$ with respect to Lagrangian axial strain $\left(\mathbf{E}_{y}\right)$ for the $R 2$ specimen

or cross linking [37]. It seems that melt processing affects the plastic parameters. Indeed after the 4-times extrusion, the $Q_{2}$ parameter and thus the drag stress decrease (Table 2). This stress represents the softening caused by plastic deformation and is clearly decreasing after the fourth extrusion; in terms of the microstructure, the drag stress represents the effect of a developing microstructure on the initial yielding behaviour.

\section{Simulation/analytical - finite element modelling}

For local modelling, the heterogeneous strain and stress induced by a curved specimen require a considerably more complicated protocol. Because of both the large strain level that was achieved and the strain gradient combined with localisation phenomena, the process used in this study is based on an iterative fine-search method. The principle of the technique is fully presented in $[26,27]$. Indeed, image analysis (IA) on the undeformed state and DIC are combined to define the shape of the sample from which a realistic mesh and a list of points where DIC can be applied are established. In this case, a post-processor for the evaluation of the local strain allows a determination of the gauge length of the two-dimensional extensometer. Depending on the meshing conditions, the smallest dimension of the gauge length is $c .1 \mathrm{~mm}$. This value is the result of mesh sensibility study; this length is sufficient to produce reproducible necking phenomenon. As explained above, the onset of the necking is not modelled by introducing a geometrical default but is a consequence of boundary conditions deduced from DIC measurements imposed on the sample boundary. At the end of the procedure, 3D displacement fields and the components of strain are computed by using the post-processor of the FE code.

Concretely, the mechanical modelling is based on the Finite Element Method (using ZeBuLON ${ }^{\circledR}$, Paris School of Mines, Paris, France [38]) and integrates both the in-plane displacement fields from DIC and the mechanical behaviour aspects. In this simulation, out-of-plane displacements are supposed to be free. It should be noted that the geometry adopted led to a quasi-square section $(4 \mathrm{~mm}$ thickness, $5 \mathrm{~mm}$ width) that promotes the validity of the assumption of transverse isotropy. To understand the local behaviour better and to simulate necking, realistic boundary conditions and geometry were used. In-plane boundaries conditions are measured by DIC. A heterogeneous prescribed displacement is applied to the boundary of the sample (see Figure 13). Finite elements analyses were realised on a 3D (1800 thetraedric elements) extruded structure because the localised necking may induce zone triaxial effect [39]. Shape, mesh of the sample and associated boundary conditions can be found in Figure 13 .

Assuming the appropriate material behaviour, the finite element solution for this simulation first confirms the localisation phenomena, even at low macroscopic strain, as well as the large strain behaviour.

The observed response from the experiments is denoted $m(t)$ at each step of time $t$ (e.g. displacements, strains and 


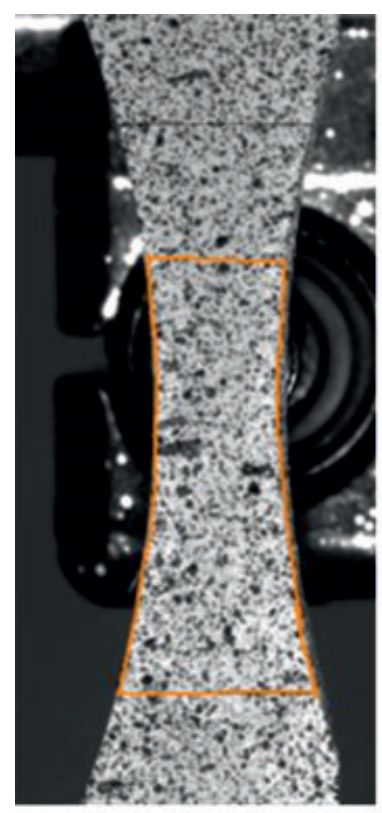

Sample shape (DIC)

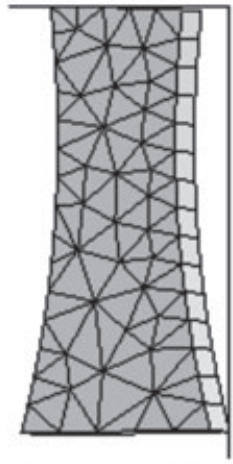

Mesh (Zebulon $\mathbb{B})$

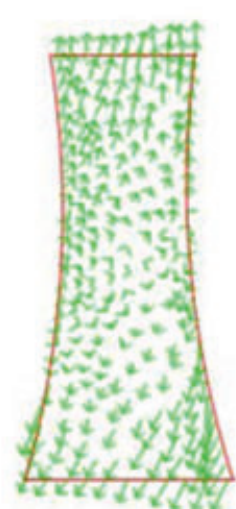

Surface prescribed displacements (DIC)

Figure 13: Mesh and boundary conditions for the finite element analysis

(A)

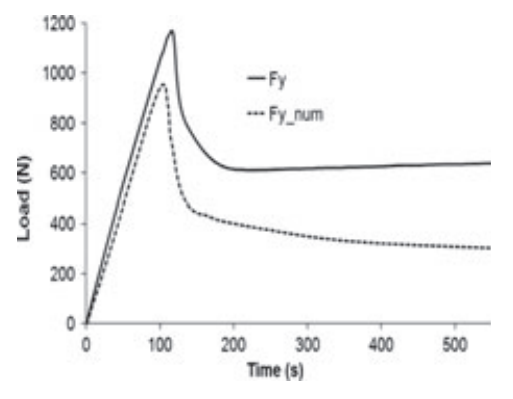

(B)

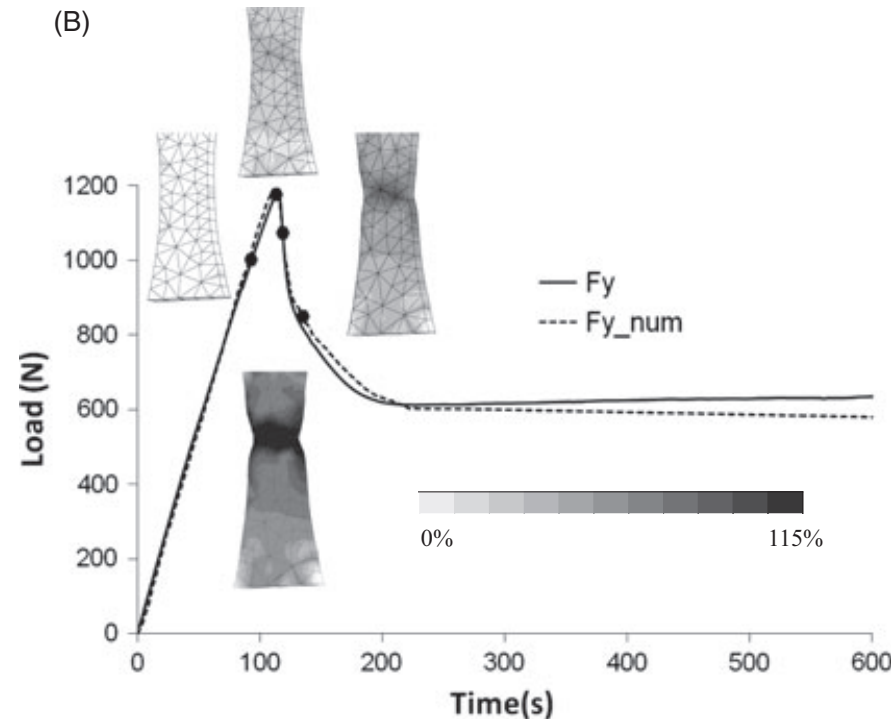

Figure 14: Local identification: evolution of experimental load $\left(\mathbf{F}_{\mathrm{y}}\right)$ and numerical load $\left(\mathbf{F}_{y_{\_} \text {num }}\right)$ versus time computed (A) with the parameters of the macro-homogeneous test $(\mathrm{B})$ after the identification procedure $(R 2)$

forces), and the corresponding information from the model is denoted $h(\boldsymbol{\theta}, t)$. A nonlinear optimisation procedure based on the Levenberg-Marquardt algorithm was used to adjust the material parameters in the FEM simulation numerically such that the calculated response matched the experimental one in a least-squares sense. This last strategy is called the FEMU approach and is fully presented in separate papers $[40,41]$. In certain cases, the authors used the Boundary Element Method (BEM) or the Virtual Fields Method (VFM) instead of the Finite Element Method, but the overall principle remains the same. An overview of the identification methods of the mechanical parameters based on full-field measurements can be found in the paper by Avril et al. [42].
A first simulation with macroscopic fitted parameters $\left(E_{0}, v_{0}, m_{1}, \alpha_{1}, m_{2}, \alpha_{2}\right.$ in Table 2$)$ was conducted and led to a load response that is underestimated for all formulations (see $F \_$num for the $R 2$ specimen in Figure 14A). Nevertheless, the model reproduces qualitatively the major aspects of the complex response that is managed by the plastic effects and volumetric changes. As a result, the straindependant elastic parameters are considered to be well fitted by the macro-homogeneous procedure. Moreover, the plastic fitted parameters are used as the initial values in the second optimisation procedure. Obviously, by considering the experimental loading curve as a target for the optimisation procedure, a set of parameters for each formulation of the FEMU procedure described in the previous section 
Table 3: Material parameters $\left(R_{0}, b_{1}, b_{2}, Q_{1}, Q_{2}\right)$ fitted into the local procedure $(R 2, R 3, R 4)$

\begin{tabular}{llllll}
\hline & $R_{0}(\mathrm{MPa})$ & $Q_{1}(\mathrm{MPa})$ & $b_{1}$ & $Q_{2}(\mathrm{MPa})$ & $b_{2}$ \\
\hline$R 2$ & 30.5 & 41.5 & 350 & -39 & 40 \\
$R 3$ & 29.6 & 43.4 & 350 & -39 & 40 \\
$R 4$ & 15.1 & 56.9 & 350 & -50 & 40 \\
\hline
\end{tabular}

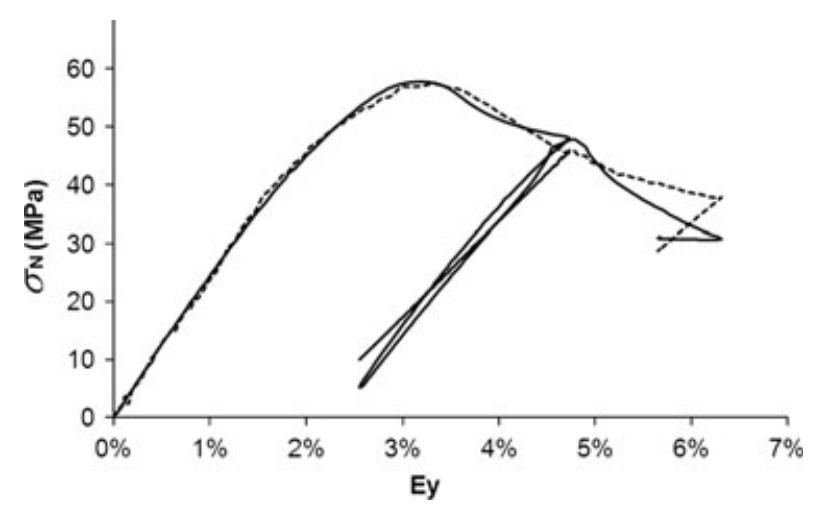

Figure 15: Experimental nominal stress (full line) and fitted nominal stress (dashed line) $\left(\sigma_{N y}\right)$ versus Lagrangian strain $\left(\mathbf{E}_{y}\right)$

can be defined. After 10 iterations, each iterative scheme produces a set of solution, each of which corresponds to a good fit (see for example Figure 14B for $R 2$ sample and the associated strain cartography). The associated results are summarised in Table 3.

Local parameter identification enables a differentiation between the samples. The plasticity parameters decrease [R0 and Q1 in Equation (11)] with the number of extrusions. The interpretation might be that the force required for the elongation of the specimens and the strain hardening increase with the number of extrusions. Obviously, this new set of parameters reproduces the global stressstrain response observed in the standardised test (see Figure 15 for the $R 2$ specimen).

\section{Conclusions}

A relevant methodology for mechanical behaviour characterisation by means of non-contact two-dimensional kinematic field measurements coupled with homogeneous and non-homogeneous tensile tests is developed. A phenomenological elastic, damageable and plastic modelling is proposed. Homogeneous tests are used to describe the strain-dependant elastic behaviour, and DIC coupled with a finite element simulation lead to the plastic parameters. The associated plasticity and damageable elasticity enable a consistent modelling of PET under localisation. This procedure allows the prediction of the local and global mechanical response of the material. Consequently, the elastic properties seem to be nearly unchanged in further reprocessing cycles, and thus, standardised tests are not able to explain the microstructural evolution associated with reprocessing. It appears that the elastic straindependant behaviour is unable to describe the microstructural changes, while the plastic parameters seem to depend on the number of extrusions. These results demonstrate that during its mechanical recycling by extrusion, PET undergoes irreversible modifications of its macromolecular structure that are induced by a variety of chemical processes. Reprocessing using data measured locally by image correlation increases the Q1-plastic coefficient (28, 31 and $47 \%$ higher for the doubly-, triply- and quadruply processed PET, respectively).

The object of future works will concern using finite element software to apply this inverse method to the microstructural processes of deformation in a damageable area that is characterised by analytical and optical measurements (e.g. SEC, IR or NMR).

\section{REFERENCES}

1. Wang, Y. Y., Chen, D. J. and Chiang, F. P. (1993) Material testing by computer aided speckle interferometry. Exp. Tech. 17, 30-32.

2. Post, D. (1983) Moire interferometry at VPI \& SU. Exp. Mech. 23, 203-210.

3. Fottenburg, W. G. (1969) Some applications of holographic. Interferometry. Exp. Mech. 8, 281-285.

4. Sutton, M. A., Turner, J. L., Bruck, H. A. and Chae, T. A. (1991) Full-field representation of discretely sampled surface deformation for displacement and strain analysis. Exp. Mech. 31, 168-177.

5. Bruck, H. A., McNeil, S. R., Sutton, M. A. and Peters, W. H. (1989) Digital image correlation using newton-raphson method of partial differential correction. Exp. Mech. 29, 261-267.

6. Castagnet, S., Gacougnolle, J. L. and Dang, P. (2000) Correlation between macroscopical viscoelastic behaviour and micromechanisms in strained $\alpha$ polyvinylidene fluoride (PVDF). Mater. Sci. Eng. A 276, 152-159.

7. Quatravaux, T., Elkoun, S., G'Sell, C., Cangemi, L. and Meimon, Y. (2002) Experimental characterization of the volume strain of poly(vinylidene fluoride) in the region of homogeneous plastic deformation. J. Polym. Sci. B 40, 2516-2522.

8. G'Sell, C., Hiver, J. M. and Dahoun, A. (2002) Experimental characterization of deformation damage in solid polymers under tension, and its interrelation with necking. Int. J. Solids Struct. 39, 3857-3872.

9. Christmann, A., Ienny, P., Quantin, J. C., Caro-Bretelle, A. S. and Lopez-Cuesta, J. M. (2011) Mechanical behaviour at large strain of polycarbonate nanocomposites during uniaxial tensile test. Polymer 52, 4033-4044.

10. Lee, B., Parks, D. and Ahzi, S. (1993) Micromechanical modelling of large plastic deformation and texture evolution in semi-crystalline polymers. J. Mech. Phys. Solids 41, 1651-1687.

11. G'Sell, C. and Dahoun, A. (1994) Evolution of microstructure in semi-crystalline polymers under large plastic deformations. Mater. Sci. Eng. A 175, 183-199.

12. Brusselle-Dupend, N., Lai, D., Feaugas, X., Guigon, M. and Clavel, M. (2001) Mechanical behavior of a semicrystalline polymer before necking. Part I: characterization of uniaxial behavior. Polym. Eng. Sci. 41, 66-76.

13. Addiego, F., Dahoun, A., G'Sell, C. and Hiver, J. M. (2006) Effect of microstructure on crazing onset in polyethylene under tension. Oil Gas Sci. Tech. 6, 715-724.

14. Challier, M., Besson, J., Laiarinandrasana, L. and Piques, R. (2006) Damage and fracture of polyvinylidene fluoride (PVDF) at $20{ }^{\circ} \mathrm{C}$ : experiments and modeling. Eng. Fract. Mech. 73, 79-90. 
15. Brusselle-Dupend, N. and Cangémi, L. (2008) A two-phase model for the mechanical behaviour of semicrystalline polymers. Part II modelling of the time-dependent mechanical behaviour of an isotropic and a highly oriented HDPE grade. Mech. Mater. 40, 761-770.

16. Zaïri, F., Naït-Abdelaziz, M., Gloaguen, J. M. and Lefebvre, J. M. (2011) A physically-based constitutive model for anisotropic damage in rubber-thoughened glassy polymers during finite deformation. Int. J. Plast 27, 25-51.

17. Lee, M. C. H. and Williams, M. C. (1985) Application of a new structural theory to polymers. I. Uniaxial stress in crosslinked rubbers. J. Polym. Sci. 23, 2243-2271.

18. Vincent, P. I. (1960) The necking and cold-drawing of rigid plastics. Polymer 1, 7-19.

19. Hall, I. H. (1967) The effect of strain rate on the stress-strain curve of oriented polymers. I. Presentation of experimental results. J. Appl. Polym. Sci. 12, 731-738.

20. Andrews, J. M. and Ward, I. M. (1970) The cold-drawing of high density polyethylene. J. Mater. Sci. 5, 411-417.

21. Meinel, G. and Peterlin, A. (1971) Plastic deformation of polyethylene. II. Change of mechanical properties during drawing. J. Appl. Polym. Sci. A 9, 67-83.

22. G'Sell, C. and Jonas, J. J. (1979) Determination of the plastic behaviour of solid polymers at constant true strain rate. $J$. Mater. Sci. 14, 583-591.

23. Nait-Ali, L. K., Colin, X. and Bergeret, A. (2011) Kinetic analysis and modelling of PET macromolecular changes during its mechanical recycling by extrusion. Polym. Degrad. Stab. 96, 236-246.

24. Awaja, F. and Pavel, D. (2005) Recycling of PET. Eur. Polym. J. 41, 1453-1477.

25. Spinacé, M. A. S. and De Paoli, M. A. (2001) Characterization of poly(ethylene terephtalate) after multiple processing cycles. J. Appl. Polym. Sci. 80, 20-25.

26. Laraba-Abbes, F., Ienny, P. and Piques, R. (2003) A new tailormade methodology for the mechanical behaviour analysis of rubber-like materials: I. Kinematics measurements using a digital speckle extensometry. Polymer 44, 807-820.

27. Laraba-Abbes, F., Ienny, P. and Piques, R. (2003) A new 'Tailormade' methodology for the mechanical behaviour analysis of rubber-like materials: II. Application to the hyperelastic behaviour characterization of a carbon-black filled natural rubber vulcanizate. Polymer 44, 821-840.

28. Parson, E. M., Boyce, M., C., Parks., D., M. and Weinberg, M. (2005) Three-dimensional large-strain tensile deformation of neat and calcium carbonate-filled high-density polyethylene. Polymer 46, 2257-2265.
29. Parson, E., Boyce, M., C., Parks. and D., M. (2004) An experimental investigation of the large-strain tensile behavior of neat and rubber-toughened polycarbonate. Polymer 45, 26652684.

30. Le Cam, J. B. and Toussaint, E. (2009) Cyclic volume changes in rubber. Mech. Mater. 41, 898-901.

31. Schultz, J. M. (1984) Microstructural aspects of failure in semicrystalline polymers. Polym. Eng. Sci. 24, 770-785.

32. Lemaitre, J. (1996) A Course on Damage Mechanics. Springer Verlag, Wien-New York.

33. Ayoub, G., Zaïri, F., Naït-Abdelaziz, M. and Gloaguen, J. M. (2010) Modelling large deformation behaviour under loadingunloading of semicrystalline polymers: application to a high density polyethylene. Int. J. Plast 26, 329-347.

34. Avila, A. F. (2001) Modeling recycled polymeric matrix composites: a social environmental solution. Polym. Plast. Technol. Eng. 40, 407-422.

35. Gaymans, R. J. (2000) Toughening of semicrystalline thermoplastics. In: Polymers Blends: Performance. (D. R. Paul and C. B. Bucknall, Eds). John Wiley and Sons, Inc., New York: 177-224.

36. La Mantia, F. P. and Gardette, J. L. (2002) Improvement of the mechanical properties of photo- oxidized films after recycling. Polym. Degrad. Stab. 75, 1-7.

37. Allen, N. S., Edge, M., Conway Doyle, D. A., Howells, E. M., Kikkawa, K., Minagawa, M. and Sekiguichi, T. (1991) Synthesis and thermal and photo-oxidative behaviour of novel 4substituted alicyclic amino-2-hydroxybenzophenone stabilizers in polypropylene films. Eur. Polym. J. 27, 1365-1371.

38. Besson, J., Leriche, R., Foerch, R. and Cailletaud, G. (1998) Application of object-oriented programming techniques to the finite element method. Part II application to material behaviors. Eur. J. Finite Elem. 7, 567-588.

39. Wattrisse, B., Chrysochoos, A., Muracciole, J. M. and NémozGaillard, M. (2001) Kinematic manifestations of localisation phenomena in steels by digital image correlation. Eur. J. Mech. A Solids 20, 189-211.

40. Ienny, P., Caro-Bretelle, A. S. and Pagnacco, E. (2009) Identification from measurements of mechanical fields by finite element model updating strategies: a review. Eur. J. Comp. Mech. 18, 353-377.

41. Giton, M., Caro-Bretelle, A. S. and Ienny, P. (2006) Hyperelastic behaviour identification by a forward problem resolution: application to a tear test of a silicone rubbers. Strain $\mathbf{4 2}$, 291-297.

42. Avril, S., Bonnet, M., Bretelle, A. S. et al. (2008) Overview of identification methods of mechanical parameters based on full-field measurements. Exp. Mech. 48, 381-402. 